\title{
NARCISISMO, O CONCEITO DE FLYING MONKEYS E O COMPORTAMENTO SOCIAL
}

Prof. Dr. Gabriel César Dias Lopes, PhD

\section{RESUMO}

O artigo em questão aborda o Transtorno de Personalidade Narcisista (TPN), enquanto patologia catalogada enquanto doença mental no DSM IV, enfocando principalmente os flying monkeys (macacos voadores), que apesar de não serem formalmente reconhecidos na medicina psiquiátrica, tem uma incidência muito grande na sociedade e com um alcance de ação negativa incalculável. Justamente por não ter esse reconhecimento, o estudo acerca de sua ação é restrito a artigos de opinião ou a chamada psicologia popular. Diante disso busca-se aqui através de uma pesquisa bibliográfica e descritiva enriquecer a literatura acerca da temática, buscando identificar e avaliar a ação e o comportamento dos flying monkeys na sociedade.

Palavras-Chave: Narcisismo, Flying Monkeys, Comportamento Social.

\section{ABSTRACT}

The article in question addresses Narcissistic Personality Disorder (TPN), as a pathology cataloged as a mental illness in DSM IV, focusing mainly on flying monkeys, which despite not being formally recognized in psychiatric medicine, have a very high 
incidence in society and with an incalculable range of negative action. Precisely because it does not have this recognition, the study of its action is restricted to opinion articles or the so-called popular psychology. Therefore, it is sought here through a bibliographic and descritive search to enrich the literature on the subject, seeking to identify and evaluate the action and behavior of flying monkeys in society.

Keywords: Narcissism, Flying Monkeys, Social Behavior.

\section{RESUMEN}

El artículo en cuestión aborda el Trastorno de Personalidad Narcisista (TPN), como una patología catalogada como una enfermedad mental en el DSM IV, centrándose principalmente en los monos voladores (monos voladores), que apesar de no ser formalmente reconocidos en medicina psiquiátrica, tienen una incidencia muy alta. en la sociedad y con un rango incalculable de acción negativa. Precisamente porque no tiene este reconocimiento, el estudio de su acción se limita a artículos de opinión o la llamada psicología popular. Por lo tanto, se busca aquí a través de una búsqueda bibliográfica y descritiva para enriquecer la literatura sobre el tema, buscando identificar y evaluar la acción y el comportamiento de los monos voladores en la sociedad.

Palabras clave: Narcisismo, Monos Voladores, Comportamiento Social.

* Gabriel César Dias Lopes é Ph.D é Graduado em: Teologia, Direito, Administração e Recursos Humanos, MBA em Marketing e Gestão Estratégica, Pós-Graduado em Psicanálise, Coordenador do Curso de Pós-Graduação Lato Sensu em Psicanálise Clínica da FABIC, Mestre em Educação, Mestre em Administração, Doutor em Educação e um Ph.D em Psicanálise pela Universidade da California. Membro da International Special Court of Arbitration and Human Rights - Registro: ISCAHRGCDL17/11n2016, Membro da Comissão Científica da Olympus Intellectual Center, Atenas (Grecia), Presidente da LUI - Logos University International. 


\section{INTRODUÇÃO}

A terminologia flying monkeys vem crescendo na chamada psicologia popular e tem chamado a atenção pois embora ainda escusada pela ciência e medicina, tem sido empiricamente comprovada em sua acepção por estar diretamente ligada à existência da personalidade narcisista. Porém como toda e qualquer transtorno de personalidade uma das suas principais questões é a identificação e o diagnóstico. Nesse sentido, o presente artigo consiste em uma revisão descritiva, que busca elucidar a definição de personalidade, transtornos da personalidade narcisista, além de discorrer sobre aspectos históricos, nosológicos e epidemiológicos. Serão revisadas as particularidades referentes ao diagnóstico, as comorbidades, ao curso e tratamento destes transtornos, com enfoque no manejo de indivíduos com TPN e o parasitismo oriundo dessa patologia que produz os flying monkeys.

\section{DEFININDO PERSONALIDADE}

Para entender o que são os transtornos de personalidade, antes é preciso definir o que caracteriza uma personalidade e quais os elementos distinguem uma personalidade saudável e uma considerada em transtorno.

Conforme (MAZER et al ,2017), personalidade pode ser definida de modo sucinto como as características individuais que correspondem a um padrão persistente de emoções, pensamentos e comportamentos. Suas características estão associadas a uma variedade importante de indicadores nos níveis individual, interpessoal e social, tais como: felicidade, saúde física e psicológica, espiritualidade e identidade; qualidade das relações familiares, amorosas e com colegas; escolha, satisfação e desempenho profissionais; envolvimento na comunidade, atividade criminosa, e ideologia política. 
Essas peculiaridades fazem de cada personalidade única e fazem com que seus traços tenham consequências. Ou seja, Personalidade é o conjunto as características de uma pessoa, o que define sua individualidade pessoal e social referente ao seu modo de sentir, pensar e principalmente agir. Trata-se de um termo abstrato pois explica e caracteriza as personalidades do indivíduo de acordo a modelos teóricos, mas que podem não abranger as especificidades e totalidade do ser humano.

\section{TRANSTORNO DE PERSONALIDADE}

Entendendo personalidade como aquilo que segue uma regra, uma teoria e um padrão, por transtorno da personalidade (TP) entende-se por sua vez aquilo que desvia, desvirtua esse padrão. Nesse caso, consiste em um "padrão persistente de experiência interna e comportamento que se desvia acentuadamente das expectativas da cultura do indivíduo, é difuso e inflexível, começa na adolescência ou início da fase adulta, é estável ao longo do tempo e leva a sofrimento ou prejuízo". (DSM, 5. 2014).

Esses transtornos ocasionam dificuldades em lidar com a vida cotidiana no que se refere às adaptações, visto que as emoções, atitudes e comportamentos acabam sendo limitadas e causa sofrimento ao individuo e ao seu entorno decorrentes das dificuldades de convívio e estresse causado por esse motivo. Na maioria dos casos é um padrão contínuo e persistente que dificulta e/ou impossibilita o indivíduo ao convívio social.

Conforme os critérios diagnósticos para um Transtorno da Personalidade, de acordo com o DSM-5, essas dificuldades geralmente se apresentam principalmente nos aspectos de cognição, afetividade, interpessoalidade e controle dos impulsos. A dificuldade nesses aspectos certamente causará dificuldades na intrapessoalidade que é a relação do indivíduo consigo mesmo.

Quando o transtorno se trata de um padrão persistente, além de atingir o individuo e comprometer seu convívio, compromete sua vida afetiva, laboral, 
causando inúmeros prejuízos, e dependendo do encaminhamento do tratamento a ser escolhido e efetivado, pode diminuir ou prolongar o sofrimento do mesmo.

\section{NARCISISMO, HISTÓRICO, NOSOLOGIA, EPIDEMIOLOGIA E TRATAMENTO}

O primeiro cientista a utilizar o termo foi Sigmund Freud (1914). Apesar das controvérsias de suas caracterizações iniciais, Freud deixa explícito de que o narcisismo é um estágio comum no desenvolvimento sexual humano que porém pode ser desenvolvido e agravado na infância. Freud articula o conceito psicanalítico do narcisismo com seu estudo do desenvolvimento infantil e dos investimentos libidinais. Assim, os investimentos libidinais podem ser direcionados ao próprio ego ou aos objetos. Quando a libido é investida no ego, diz libido do ego ou libido narcísica (FREUD, 1914).

Para Freud, todo o processo narcísico desenvolvido na infância, tem sua articulação com a relação da criança com os pais e com a forma com que esses se relacionam com as aquisições e perdas e com todo seu entorno sociocultural. Mesmo sem nos adentrarmos na teoria freudiana propriamente dita, fica claro em sua exposição que o narcisismo tem origem na infância e se desenvolve com as relações dos indivíduos no ambiente. (FACHINI,1996).

Contrário à teoria de Freud, e caracterizado no DSM IV, com o CID.10 é F60.8 - 301.8, o Transtorno de Personalidade Narcisista ou Narcisismo tem origem na idade adulta e é caracterizado por um padrão invasivo de grandiosidade, necessidade de admiração e falta de empatia e está presente em uma variedade de contextos.(DSM,2014).

As principais características dos indivíduos com este transtorno são à primeira vista arrogantes, presunçosos, vaidosos, megalomaníacos e geralmente e exageram suas realizações. Sua vaidade chega ao ponto de entenderem que os outros os veem da mesma forma que eles mesmos se veem e não aceitam bem o fato de não se 
perceberem valorizados. Frequentemente menosprezam a ajuda e a contribuição de outrem ao supervalorizarem seus feitos. (ARAÚJO,2010).

$\mathrm{Na}$ esteira de sua vaidade, fantasiam com poder e sucesso ilimitados e em termos de comparação própria só o fazem com quem está em destaque e claro, demonstrando vantagem sobre esses. Consideram-se superiores e, portanto, esperam esse reconhecimento por todos, associando-se apenas com quem lhes seja par. Acreditam ter necessidades especiais, que estão além do entendimento das pessoas comuns. Sua própria autoestima é amplificada (isto é, "espelhada") pelo valor idealizado que atribuem àqueles a quem se associam e é nesse contexto que surgem os flyying monkeys, que consciente ou involuntariamente fazem parte do séquito de admiradores.

Não é qualquer pessoa que se associa ao narcisista. Ele só se associa com quem acha digno de sua presença e atenção, portanto, ao se associar com os melhores suas credenciais serão amplificadas também pelos melhores. Por possuir uma autoestima vulnerável sob a capa da vaidade, sua necessidade de atenção e admiração excessiva gera ira, fúria e raiva quando não obtém a deferência desejada.

Frequentemente suas relações pessoais são baseadas em jogo de interesses nos quais por se vislumbrarem seres especiais requerem privilégios e recursos extras de outrem para atender seus objetivos. Sua falta de empatia e alteridade fazem com que acredite que os outros vivem em torno de suas necessidades e problemas. Assim não percebem nem ao mesmo quando esse comportamento magoa e causa estresse em outrem. (ARAÚJO, 2010).

São considerados assim frios emocionalmente e acreditam que são invejados por todos, desenvolvendo inveja e rancor pelo sucesso e felicidade dos outros. Como dito anteriormente por conta dessa vaidade e arrogância sua vulnerabilidade é a crítica e o insucesso, que podem levar o individuo desde um retraimento e isolamento social temporário ou a uma falsa modéstia e humildade como forma de mascarar seu sentimento de humilhação.

Profissionalmente, esse indivíduo para evitar críticas e derrota, não se arrisca muito, levando-o a ter um desempenho medíocre, outras associações para esse 
sentimento de derrota são humor deprimido, e Transtorno Depressivo Maior ou Distímico. Por outro lado, períodos persistentes de grandiosidade podem estar associados com um humor hipomaníaco. O Transtorno da Personalidade Narcisista também está associado com Anorexia Nervosa e Transtornos Relacionados a Substâncias (especialmente relacionados à cocaína). Os Transtornos da Personalidade Histriônica, Borderline, Anti-Social e Paranóide podem estar associados com o Transtorno da Personalidade Narcisista. (DSM, 2014).

Estatisticamente atribuem aos homens maior incidência do Transtorno de Personalidade Narcisista. Os homens perfazem 50 a 75\% dos indivíduos, sendo que contrariando os estudos de Freud, estudos atribuem que é entre a adolescência e avida adulta que ela se origina. As estimativas da prevalência do Transtorno da Personalidade Narcisista variam de 2 a 16\% na população clínica e são de menos de $1 \%$ na população geral. Outra questão inerente ao transtorno é que ao ser atingido pelo envelhecimento o narcisista tem ainda mais sua funcionalidade laboral comprometida.

\section{ESPECIFICIDADE DO DIAGNÓSTICO}

Como dito anteriormente uma das características dos transtornos mentais são sua dificuldade de diagnóstico. Diversos transtornos mentais podem ser confundidos com o TPN, porém conforme orientação psiquiátrica a grande diferenciação está na observação de traços como sedução, indiferença, vaidade, insensibilidade, orgulho e megalomania.

O Transtorno da Personalidade Narcisista deve ser diferenciado de uma Alteração da Personalidade Devido a uma Condição Médica Geral, na qual os traços emergem devido aos efeitos diretos de uma condição médica geral sobre o sistema nervoso central. Muitos indivíduos altamente bem-sucedidos exibem traços de personalidade que poderiam ser considerados narcisistas, porém estes traços somente constituem um Transtorno da Personalidade Narcisista quando são 
inflexíveis, mal-adaptativos e persistentes e causam prejuízo funcional significativo ou sofrimento subjetivo. (MAZER, 2017).

Diagnóstico de transtorno de personalidade deve ser considerado em pacientes "difíceis", mas exige uma avaliação longitudinal e independente de sintomas de depressão, ansiedade, uso de substâncias e outros transtornos mentais, que são comorbidade frequentes. Os princípios gerais de abordagem de pacientes com transtornos de personalidade incluem uma atitude coerente, confiável, não confrontadora e não julgadora, cuidando para que o estigma não prejudique o investimento em tratamentos disponíveis.

\section{FLYING MONKEYS, O QUE SÃO?}

Em termos psicológicos o conceito de personalidade designa, de maneira muito geral, a unidade individual do comportamento e do seu fundamento interno, ou seja, designa a conformidade de um determinado comportamento com o seu fundamento interno, sendo este do foro individual e psicológico de um indivíduo dado. (MAZER, 2017).

Enquanto a sociologia se ocupa da manifestação exterior da personalidade, a psicologia interessa-se mais pela relação de personalidade dentro do próprio indivíduo. Analisa como ela se manifesta exteriormente e antes observar ou analisar a conformidade existente entre aquilo que é a manifestação exterior do comportamento de um dado indivíduo e aquilo que se pensa que esse mesmo indivíduo é, em si, dentro de si. (MAZER, 2017).

O termo e o conceito de flying monkeys, originariamente retirado do filme $\mathrm{O}$ mágico de Oz (1939) é assim utilizado para retratar aqueles que faziam o trabalho por procuração, as sujeiras da bruxa malvada. Na psicologia a existência do flying monkey é análogo a existência do narcisista e se pode declarar que é uma relação parasitária, simbiótica em que um não funciona sem o outro. 
Quanto à identidade esses sujeitos são aqueles que acreditam e alimentam o ego do narcisista, seja manipulada involuntariamente ou seja condescendentemente aquiescendo e na verdade se beneficiando da relação e em alguns casos também desenvolvendo uma personalidade narcisista.

Quanto a procedência esses sujeitos podem ser desde familiares, cônjuges, até colaboradores, funcionários, prestadores de serviços, enfim todos que alimentem o ego narcisista de alguma forma. São popularmente chamados também de abusadores de proxy pois se associam ao narcisista para infligir punições, castigos, tormentas a outrem. Essas ações podem ser desde calúnias, difamações, a espionagem, manipulação por procuração (proxy), para atender as necessidades do narcisista.

São essas personalidades que adquirem a causa do narcisista e a tomam para si, isentando-o de responsabilidades do trabalho sujo e como dito anteriormente isso pode ser consentido ou involuntário. Pela própria natureza do narcisista ele pode agregar um ou vários flying monkeys que agem como grupo de apoio motivados por necessidade financeira, ilusão romântica, co- dependência ou mesmo por vaidade em fazer parte do grupo de um narcisista maior.

\section{A ABORDAGEM DA PSICANÁLISE}

A abordagem para o tratamento dos transtornos mentais por si só é dificultada pela aceitação e compreensão do indivíduo acerca do seu transtorno. A personalidade narcisista encontra na própria vaidade essa barreira visto que o sujeito não percebe seu comportamento como disfuncional, mas como um símbolo de sua perfeição e especificidade. Para casos não muito graves talvez a psicoterapia ajude. Mas é preciso entender que alguns casos se tornam intratáveis.

Nos casos em que há a procura pelo tratamento, a psicoterapia se apresenta como a decisão mais coerente no tratamento do distúrbio da personalidade narcisista. Nesse caso, a terapia cognitivo comportamental pode ser usada para ajudar o sujeito 
a se perceber como realmente é, sem as ilusões de grandeza e a aprender como se relacionar melhor com os outros, a fim de estimular relacionamentos interpessoais mais funcionais e obter uma melhor compreensão de suas emoções.

No caso dos flying monkeys a questão perpassa pela sua própria percepção da situação de manipulado e que procure a terapia para entender os motivos que o levam a tal comportamento que, ainda que com dividendos em curto prazo certamente trará mais prejuízos à sua vida e ao seu mundo emocional. Um narcisista pode formar uma família de narcisistas e que terão um séquito de flying monkeys, pessoas adoecidas e que geram doenças.

Alguns tratamentos em evidência são a terapia de mentalização que se concentra sobre esse aspecto e utiliza várias intervenções para desenvolver a mentalização dos pacientes; Psicoterapia focada na transferência que envolve a exploração de um segredo (do mundo interior dos pacientes) para avaliar suas crises de identidade. A terapia tenta promover a integração de identidade; Psicoterapia focada em esquemas que foca mais as necessidades básicas do paciente e na ativação de emoções. A terapia se apropria de uma série de abordagens cognitivocomportamentais, experimentais, interpessoais e psicanalíticas para tratamento; Psicoterapia analítica funcional onde os comportamentos exibidos pelo paciente durante as sessões são considerados exemplos dos mesmos problemas comportamentais que se manifestam em outros relacionamentos interpessoais. Assim, a tarefa do terapeuta consiste em descobrir como esses problemas ocorrem, ajustando os comportamentos interpessoais do paciente de um modo mais efetivo e por fim a Terapia comportamental dialética (TCD) que se concentra na aceitação e mudança dos pacientes. As estratégias de tratamento exploram vários princípios, como os princípios cognitivo-comportamentais voltados à alteração de comportamento. (RODRIGUES, 2017). 


\section{CONSIDERAÇÕES FINAIS}

O flying monkey é aquele visto por alguém de fora. Quando inserido na relação parasitária com o narcisista, dependendo da motivação ele não se percebe. Para a terapia o ideal é que esse indivíduo perceba sua condição e busque ajuda psicoterápica para avaliar as condições emocionais e psicológicas que o submetem a tal relacionamento.

Do ponto de vista social o que se pode dizer é que esse indivíduo é tão perigoso quanto o narcisista, porque ao buscar a aprovação desse, é capaz de tudo para se sentir parte do processo e em uma relação parasitária como foi dito também busca o lucro dessa relação seja pelo sentimento de pertencimento , seja por motivação material. 


\section{REFERÊNCIAS}

ASSOCIAÇÃO AMERICANA DE PSIQUIATRIA. Manual diagnóstico e estatístico dos transtornos mentais $-5^{\mathrm{a}}$ ed. (DSM-5): Editora, Artmed; 2014.

https://www.msdmanuals.com/pt-br/profissional/transtornos-psiquiátricos/transtornosde-personalidade/transtorno-de-personalidade-narcisista-tpn 2/2

ARAUJO, Maria das Graças. Considerações sobre o narcisismo. Estud. psicanal., Belo Horizonte , n. 34, p. 79-82, dez. 2010 . Disponível em http://pepsic.bvsalud.org/scielo.php?script=sci arttext\&pid=S010034372010000200011\&lng=pt\&nrm=iso Acesso em 12 abr. 2020.

FACHINI, N. Narcisismo e Clínica. Estudos de Psicanálise. Belo Horizonte, n. 19, p. 48- 52, set. 1996.

FREUD, S. [1914]. Sobre o narcisismo: uma introdução. In: Edição standard brasileira das obras psicológicas completas. 1. ed. Trad. Jayme Salomão. Rio de Janeiro: Imago, 1974, v. XIV, p. 85-119.

MAZER AK, MACEDO BBD, JURUENA MF. Transtornos da Personalidade. Medicina (Ribeirão Preto, Online.) 2017;50 (Supl.1),jan-fev.:85-97 http://dx.doi.org/10.11606/issn.2176-7262.v50isupl1.p85-97

Fonte: 5 Tratamentos para Transtorno de Personalidade Narcisista

https://www.educarsaude.com/tratamento-para-transtorno-de-personalidadenarcisista/ | Revisado por Reinaldo Rodrigues (Enfermeiro - Coren no 491692) 